\title{
COMPARISON OF A DIGESTION-SEDIMENTATION TECHNIQUE WITH THE KaTO-Katz TECHNIQUE IN THE DETECTION AND QUANTIFICATION OF S. MANSONI EGGS IN LIGHT TO MODERATE INFECTIONS
}

\author{
BOREL E.*, ETARD J.-F.**, ADDO A.* \& DIAKITE M.***
}

\begin{abstract}
Summary :
A comparison between a digestion-sedimentation technique (DST) and the Kato-Katz thick smear technique (KKT) in the detection and quantification of Schistosoma eggs in stool was carried out in 551 subjects. Specimen were collected one or two years after treatment with praziquantel from subjects living in a schistosomiasis endemic area of Mali. One hundred infections missed by the KKT were detected by the DST. Conversely, 35 infections missed by the DST were detected by the KKT (88\% were light infections). More subjects were classified as lightly infected by the DST $\left|p<10^{-3}\right|$ and more subjects were classified as moderately infected (101-400 epg) by the KKT (p=0.02). The KKT produced higher counts than the DST among the youngest age group which was also the most infected. The principal advantage of the DST over the KKT was its better sensitivity to detect light infections resulting from a larger amount of stool processed.
\end{abstract}

KEY WORDS : Schistosoma mansoni, diagnosis, sedimentation, Kato, Mali. MOTS CLÉS : Schistosoma mansoni, diagnostic, sédimentation, Kato, Mali.

$\mathrm{P}$ revalence rate and intensity of infection with S. mansoni, measured by direct parasitological techniques, are widely used to collect baseline infection data in a community or to monitor a control programme. The simplicity and low cost of the KatoKatz technique justify its recommendation for field work. However, single-stool surveys show a low sensitivity in detecting light schistosome infections (Knight et al., 1976). Underestimation of the proportion of

\footnotetext{
- Université C. Bernard/Laboratoire de Parasitologie et Mycologie Médicale, 8, avenue Rockefeller, 69373 Lyon Cedex 08, France.

" Institut de Recherche pour le Développement (IRD, anciennement ORSTOM)/Institut National de Recherche en Santé Publique (INRSP), BP 1771, Bamako, Mali.

-. Faculté de Médecine de Pharmacie et d'Odonto-stomatologie/ Département d'Epidémiologie des Affections Parasitaires, BP 1805, Bamako, Mali. Correspondence: Jean-François Etard. IRD, BP 1386, Dakar, Sénégal. Tél. : +2218323480 - Fax : +2218324307

E-mail : Jean-Francois.Etard@ird.sn
}

Résumé : COMPARAISON DE LA TECHNIQUE DE DIGESTIONSÉDIMENTATION À LA TECHNIQUE DE KaTO-KATZ POUR LA DÉTECTION ET LA QUANTIFICATION DES CEUFS DE S. MANSONI

Une technique de digestion-sédimentation a été comparée à la technique de Kato-Katz pour la détection des œufs de Schistosoma mansoni chez 551 sujets vivant en zone d'endémie bilharzienne au Mali et traités par du praziquantel un à deux ans auparavant. Cent infections, non identifiées par la technique de Kato-Katz, l'ont été par digestion-sédimentation. Inversement, 35 infections non diagnostiquées par digestion-sédimentation l'ont été par la technique de Kato-Katz (faible intensité dans $88 \%$ ). Plus de sujets ont été classés dans la catégorie des faibles intensités par digestion-sédimentation $\left(p<10^{-3}\right)$ et plus de sujets dans la catégorie des intensités modérées par Kato-Katz $(p=0,02)$. La technique de Kato-Katz a produit des comptes d'œufs plus élevés que la digestion-sédimentation chez les sujets les plus jeunes $16-$ 9 ans), par ailleurs les plus intensément infectés. Le principal avantage de la digestion-sédimentation sur le Kato-Katz sur un prélèvement unique de selles était sa meilleure sensibilité pour détecter les faibles infections du fait d'une quantité plus importante de selles examinées. infected individuals, particularly when low infections are expected, such after chemotherapy, is then likely. Part of the bias is explained by the short-term variability in egg output within individuals (Barreto et al., 1990). Although the sensitivity of the sedimentation techniques in detecting heavy eggs, such as schistosome eggs, has been recognized for many years (Faust, 1946), the processing time and the numerous manipulations prevented their use in large populationbased surveys.

We report here a comparison of a digestion-sedimentation technique (DST) with the Kato-Katz technique (KKT) in a context of low intensity of infection.

\section{MATERIALS AND METHODS}

\section{STUDY DESIGN}

Dield work was carried out in the "Office du 4 Niger", Mali, an irrigated rice-growing area in Central Mali where both S. mansoni and S. hae- 
matobium infections are present (Brinkmann et al., 1988). This work was part of a larger study on the socio-economic impact of schistosomiasis approved by the "Programme National de Lutte Contre les Schistosomiases (PNLCS)" (Audibert \& Etard, 1998). A subset of 623 subjects from the main random sample were included in this study. They had previously received a single dose of $40 \mathrm{mg} \cdot \mathrm{kg}^{-1}$ of praziquantel under medical supervision either in December 1989 (mass treatment) and December 1990 (selective treatment) or in December 90 (mass treatment). In December 1991, egg counts using the DST and the KKT were performed. Those found infected received a dose of praziquantel.

\section{LABORATORY PROCEDURE}

Individuals were asked to provide a stool sample on the night before the examination. The specimen were transported to the laboratory on the morning and processed. The KKT and the DST were performed in a blind fashion by two independent teams.

The KKT was performed by the PNLCS team: $40 \mathrm{mg}$ of calibrated sieved faeces, clearance of the smears for one to two hours, reading by three experienced technicians.

The DST followed the procedure described by Shidam (1991): $300 \mathrm{mg}$ stool specimen using $4 \%$ potassium hydroxide for digestion, one or two smears depending on the volume of the sediment, reading by one investigator (E.B.) at a magnitude of $\times 10$ or $\times 25$, addition of the egg counts in case of two smears.

\section{STATISTICAL ANALYSIS}

The number of eggs per gram (epg) was computed after multiplication of the eggs counts by 3.33 (DST) or 25 (KKT). Intensity of infection was categorized in four levels: no infection, light infection (1-100 epg), moderate infection (101-400 epg) and severe infection (> 400 epg). Geometric means after Ln (egg counts + 1) transformation, McNemar, paired t-test, Wilcoxon signed-ranks test for paired-sample and correlation coefficient were used.

\section{RESULTS}

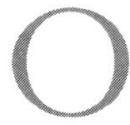

$\mathrm{n}$ the average, 80 samples were processed per day. DST data were obtained from 623 subjects and KKT from 554. Analysis was performed on 551 complete data set.

More cases were detected by the DST than by the KKT (Table I). The overall difference in the proportion of detected infections was $11.8 \%$ (McNemar $\mathrm{X}^{2}=31.3$, $\left.\mathrm{p}<10^{-3}\right)$. One hundred infections detected by the DST

\begin{tabular}{ccccccc}
\hline & \multicolumn{3}{c}{ KKT $^{*}$} & \multicolumn{3}{c}{ Total } \\
\cline { 2 - 7 } DST $\boldsymbol{n y y y y y}$ & $0 \neq$ & $1-100$ & $101-400$ & $>400$ & No & $\%$ \\
\hline 0 & 233 & 31 & 4 & 0 & 268 & 48.6 \\
$1-100$ & 97 & 86 & 40 & 1 & 224 & 40.7 \\
$101-400$ & 3 & 17 & 19 & 8 & 47 & 8.5 \\
$>400$ & 0 & 0 & 4 & 8 & 12 & 2.2 \\
Total & & & & & & \\
No & 333 & 134 & 67 & 17 & 551 & 100 \\
$\%$ & 60.4 & 24.3 & 12.2 & 3.1 & 100 & \\
\hline
\end{tabular}

* Kato-Katz technique

† Digestion-sedimentation technique

‡ Eggs/gram (epg)

Table I. - Cross-classification of the infection grades, Office du Niger, Mali, 1991, 551 subjects.

were missed by the KKT, $97 \%$ of these missed infections being classified as light infection by the DST. On the other hand, 35 infections detected by the KKT were left undetected by the DST. However, $75 \%$ of the DSTfalse negatives corresponded to one or two eggs per Kato smear and $88 \%$ corresponded to light infections in KKT. In terms of infection grades, significantly more infections were classified as light by the DST than by the KKT (40.6\% vs $24.3 \%$, McNemar $\mathrm{X}^{2}=43.5$, $\mathrm{p}<10^{-3}$ ). Conversely, the number of infections classified as moderate was 1.4 time higher by the KKT than by the DST (12.1\% vs $8.5 \%$, McNemar $\mathrm{X}^{2}=5.3$, $p=0.02$ ). Above 400 epg, no difference was shown. Correlation between the Ln-transformation of egg counts was good $\left(r=0.68 ; \mathrm{p}<10^{-3}\right)$.

When the results were stratified by age, the proportion of positive cases detected by the DST was greater in all age groups except among the six to nine years old children where no difference was observed (Table II). In terms of intensity of infection, the association was reversed: the overall intensity of infection did not differ and the stratification by age revealed a difference among the six to nine years old children, the KKT intensity being higher than the DST intensity $\left(\mathrm{p}<10^{-2}\right)$.

\section{DISCUSSION}

The assessment of light infections with S. manson $i$ within an endemic community or the evaluation of a population-based chemotherapy require a sensitive and easily performed parasitological technique under the field conditions.

Our results show that, except among the six to nine years old children, a single digestion-sedimentation detected more infections than a single Kato-Katz smear and that both techniques reported the same overall 


\begin{tabular}{|c|c|c|c|c|c|c|c|}
\hline \multirow[b]{2}{*}{ Age } & \multirow[b]{2}{*}{ No. of patients } & \multicolumn{3}{|c|}{$\begin{array}{c}\text { No. Infected } \\
\%+v e\end{array}$} & \multicolumn{3}{|c|}{$\begin{array}{c}\text { Mean Ln (SD) } \\
\text { GM } \dagger\end{array}$} \\
\hline & & DST & KKT & $X^{2}$ & DST & KKT & t-test/nonpar $\neq$ \\
\hline $6-9$ & 103 & $\begin{array}{c}77 \\
74.8\end{array}$ & $\begin{array}{c}73 \\
70.9\end{array}$ & NS & $\begin{array}{c}2.74(2.01) \\
15.5\end{array}$ & $\begin{array}{c}3.33(2.32) \\
27.9\end{array}$ & $* * *$ \\
\hline $10-14$ & 82 & $\begin{array}{c}66 \\
80.5\end{array}$ & $\begin{array}{l}51 \\
62.2\end{array}$ & $* * *$ & $\begin{array}{c}2.73(1.82) \\
14.8\end{array}$ & $\begin{array}{c}2.80(2.34) \\
17.1\end{array}$ & NS \\
\hline 15-19 & 55 & $\begin{array}{c}33 \\
60.0\end{array}$ & $\begin{array}{c}23 \\
41.8\end{array}$ & $* *$ & $\begin{array}{c}1.85(1.86) \\
6.4\end{array}$ & $\begin{array}{c}1.94(2.37) \\
6.9\end{array}$ & NS \\
\hline$>20$ & 311 & $\begin{array}{l}107 \\
34.4\end{array}$ & $\begin{array}{c}71 \\
22.8\end{array}$ & $* * * *$ & $\begin{array}{c}1.05(1.69) \\
2.8\end{array}$ & $\begin{array}{c}0.98(1.86) \\
2.7\end{array}$ & NS \\
\hline Total & 551 & $\begin{array}{l}283 \\
51.4\end{array}$ & $\begin{array}{l}218 \\
39.6\end{array}$ & ***** & $\begin{array}{c}1.69(1.95) \\
5.4\end{array}$ & $\begin{array}{c}1.78( \pm 2.29) \\
5.9\end{array}$ & NS \\
\hline
\end{tabular}

$\dagger$ Geometric mean including zero egg counts; $\neq$ Paired t-test and Wilcoxon signed-ranks for paired sample; ${ }^{* *} 0.01<\mathrm{p}<0.05$; *** $10^{-3}<\mathrm{p}<10^{-2} ;{ }^{* * * *} \mathrm{p}<10^{-3}$.

Table II. - Number of detected infections and density of infection by age group and technique, Office du Niger, Mali, 1991,551 subjects.

intensity of infection. Although age was clearly related to prevalence and intensity of infection, it could not have generated a differential bias between the techniques: the laboratory technicians did not know the age and gender of the subjects and the laboratory procedures were standardized. It has been reported that the KKT tends to overestimate the intensity of infection and has a better sensitivity in groups of heavily infected subjects (Sleigh et al., 1982). This is what probably happened among the youngest children.

The overall better sensitivity of the DST could be primarily explained by the larger amount of stools processed (300 mg vs $40 \mathrm{mg}$ ). Indeed, assuming a Poisson distribution of eggs in stool and no loss of eggs due to the technique, one can show that, for a given density of one egg/ $40 \mathrm{mg}$ of faeces, the probability to detect one egg is $99 \%$ and $64 \%$ for processing $300 \mathrm{mg}$ and $40 \mathrm{mg}$ of faeces respectively.

Of more concern were the 35 subjects left undetected by the DST but classified as infected by the KKT. Our preliminary testing of the DST, in the experimental setting of a university laboratory, have shown that no eggs remained in the sieving device after processing a stool sample, so that a loss in eggs during the manipulation was ruled out. However, under field conditions, this hypothesis must be considered. Given the experience of the technicians, Kato-Katz false positives is not a plausible alternative.

The implementation of the DST in a field laboratory presented no practical difficulty and required no highqualified personnel. The time required for the digestion and sedimentation phases was rewarded by an ease of microscopy reading, even at a magnitude of $\times 10$. The DST allowed a perfect distinction between the species of schistosomes, which could be worth in areas where $S$. mansoni and $S$. haematobium are both present, such as the Office du Niger in Mali.

Although the lack of sensitivity of a single Kato-Katz smear is widely recognized (De Vlas \& Gryseels, 1992), this technique remains useful in large screening surveys in highly endemic areas where high sensitivity is not crucial and remains the first choice for community investigation of soil-transmitted nematodes. To improve the case detection rate of the KKT, several stool samples obtained on consecutive days can be examined (Barreto et al., 1990); however, this procedure is time-consuming, expensive and often come up against a refusal from the villagers. Assuming that the parasite population is best described by the negative binomial distribution (Bliss \& Fisher, 1953) helps to infer true prevalences from observed data. A pocket chart, based on this distribution, has been proposed to estimate the true S. mansoni prevalences from single-stool surveys (De Vlas et al., 1993). The use of this chart is appealing but requires comparison of the predicted true prevalence with observed prevalence derived from sensitive technique, such as the DST described here.

\section{ACKNOWLEDGEMENTS}

1 The study was supported by grants from CFD, GTZ, ECC, UNICEF and OSI Laboratory. We wish to thank Dr M. Traoré (INRSP, Mali) and

Dr M. Audibert (CNRS/CERDI, Clermont-Ferrand) who permitted this study. Kato-Katz examinations and treatment were carried out by the team of the "Programme National de Lutte Contre les Schistosomiases" (INRSP, Mali) and the "Département d'Epidémiologie des Affections Parasitaires" (Faculté de Médecine, Mali). Thanks are due to Dr D. de Clercq for reading of the manuscript. 


\section{REFERENCES}

Audibert M. \& ETARD J.F. Impact of schistosomiasis on rice output and farm inputs in Mali. Journal of African Economies, 1998, 7, 185-207.

Barreto M.L., Smith D.H. \& Sleigh A.C. Implications of faecal egg cout variation when using the Kato-Katz method to assess Schistosoma mansoni infections. Transactions of the Royal Society of Tropical Medicine and Hygiene, 1990, 84, 554-555.

Bliss C.J. \& Fisher R.A. Fitting the negative binomial distribution to biological data. Biometrics, 1953, 9, 176-196.

Brinkmann U.K., Korte R. \& Schmidt-Ehry B. The distribution and spread of schistosomiasis in relation to water resources development in Mali. Tropical Medicine and Parasitology, 1988, 39, 182-185.

DE Vlas S.J. \& Gryseels B. Underestimation of Schistosoma mansoni prevalences. Parasitology Today, 1992, 8, 274277.

De Vlas S.J., Gryseels B., Van Oortmarssen G.J., Polderman A.M. \& Habbema J.D.F. A pocket chart to estimate true Schistosoma mansoni prevalences. Parasitology Today, 1993, 9, 305-306.

Faust E.C., Ingalls J .W. \& SEe J.K. The diagnosis of schistosomiasis. III. Technics for the recovery of the eggs of Schistosoma japonicum. American Journal of Tropical Medicine and Hygiene, 1946, 26, 559-584.

Knight W.B., Hiatt R.A., Cline B.L. \& Ritchie L.S. A modification of the formol-ether concentration technique for increased sensitivity in detection of Schistosoma mansoni eggs. American Journal of Tropical Medicine and Hygiene, 1976, 25, 818-823.

SHIDAm V.B. A rapid, economical, and simple method for concentration of Schistosoma mansoni ova in faeces. American Journal Clinical of Pathology, 1991, 95, 91-95.

Sleigh A., Hoff R., Mott K.E., Barreto M., Maisk de Paiva T., Sonza Pedrosa S. \& Sherlock I. Comparison of filtration staining (Bell) and thick smear (Kato) for the detection and quantification of Schistosoma mansoni eggs in faeces. Transactions of the Royal Society Tropical of Medicine and Hygiene, 1982, 76, 403-406.

Reçu le 4 février 1998 Accepté le 14 janvier 1999 